\title{
The effect of molecular mass on the polymorphism and crystalline structure of isotactic polypropylene
}

\author{
Zs. Horváth ${ }^{1}$, I. E. Sajón ${ }^{2}$, K. Stoll ${ }^{3}$, A. Menyhárd ${ }^{1,4}$, J. Varga ${ }^{1}$ \\ ${ }^{1}$ Budapest University of Technology and Economics, Department of Physical Chemistry and Materials Science, \\ P. O. Box 91, H-1521 Budapest, Hungary \\ ${ }^{2}$ Hungarian Academy of Sciences, Chemical Research Centre, Institute of Nanochemistry and Catalysis, P. O. Box 17, \\ H-1525 Budapest, Hungary \\ ${ }^{3}$ CIBA Inc, Schwarzwaldallee 215, CH-4002 Basel, Switzerland \\ ${ }^{4}$ Hungarian Academy of Sciences, Chemical Research Centre, Institute of Materials and Environmental Chemistry, \\ P. O. Box 17, H-1525 Budapest, Hungary
}

Received 5 May 2009; accepted in revised form 5 December 2009

\begin{abstract}
This study is devoted to the investigation of the effect of molecular mass on the $\alpha$-, $\beta$ - and $\gamma$-crystallization tendency of isotactic polypropylene (iPP). The crystalline structure was studied by wide angle X-ray scattering (WAXS) and by polarised light microscopy (PLM). The melting and crystallization characteristics were determined by differential scanning calorimetry (DSC). The results indicate clearly that iPP with low molecular mass crystallizes essentially in $\alpha$-modification. However, it crystallizes in $\beta$-form in the presence of a highly efficient and selective $\beta$-nucleating agent. The $\alpha$ - and $\beta$-modifications form in wide molecular mass range. The decreasing molecular mass results in increased structural instability in both $\alpha$ - and $\beta$-modifications and consequently enhanced inclination to recrystallization during heating. The formation of $\gamma$-modification could not be observed, although some literature sources report that $\gamma$-form develops in iPP with low molecular mass.
\end{abstract}

Keywords: thermal properties, isotactic polypropylene, low molecular mass, crystallization tendency, polymorphism

\section{Introduction}

Semicrystalline isotactic polypropylene (iPP) is a commodity polymer produced and applied in large quantity nowadays. Semicrystalline iPP is a polymorphic material, with several crystalline modifications including the monoclinic $(\alpha)$, the trigonal $(\beta)$, and the orthorhombic $(\gamma)$ forms [1-4]. iPP crystallizes essentially into $\alpha$-modification under traditional processing conditions. The $\alpha$-form is the thermodynamically stable form according to the literature $[1,3,4]$. The modification of the crystalline structure of iPP by introduction of nucleating agents is one of the keys of its wide scale application fields.
The $\beta$-form of iPP ( $\beta$-iPP) can be prepared by adding $\beta$-nucleating agents in the industrial practice [4]. Several efficient and selective $\beta$-nucleating agents are known in the literature [4-13]. However, more or less $\alpha$-iPP is always formed in their presence $[5,7-10]$. The pure $\beta$-form of iPP was prepared by Varga et al. [11] by the introduction of Ca-salt of suberic or pimelic acids. Recently, Zhang et al. $[12,13]$ used pimelic acid supported nano-sized $\mathrm{CaCO}_{3}$ as $\beta$-nucleating agent. $\beta$-iPP has several advantageous properties compared to the traditional $\alpha$-form, like higher impact resistance, ductility and better weldability $[4,14,15]$. The high impact resistance of $\beta$-form resulted in increased 
industrial interest in the past decades and simultaneously the number of available $\beta$-nucleating agents increased as well.

The early studies revealed that iPP with low molecular mass $\left(M_{w}<6000 \mathrm{~g} / \mathrm{mol}\right)$ results in the formation of samples rich in $\gamma$-iPP [16-18]. The effect of molecular mass on the crystalline morphology in non-nucleated and $\beta$-nucleated peroxide degraded iPP has been studied by Wang et al. [19]. However, they carried out studies only in a narrow molecular mass range, where no significant changes were observed. Moreover, the effect of $\beta \alpha$-recrystallization was not eliminated during their DSC studies in the case of $\beta$-nucleated samples. Recently, Chvatalova et al. [20] reported a detailed study about the effect of molecular mass on the $\beta$-crystallization ability of iPP. They performed their study using commercial iPP grades with different molecular masses and applied a commercial $\beta$-nucleating agent.

It was also observed that during the crystallization of degraded iPP samples with enhanced content of $\gamma$-form were formed. Vychopnova et al. [21] have investigated the effect of photo-degradation on the crystallization tendency of $\beta$-nucleated iPP. They found that the crystallization tendency in the $\beta$ - and $\alpha$-forms decreases with increasing doses of irradiation, but they have not studied the polymorphic composition by WAXS technique. Therefore, they could not obtain any information about the formation of $\gamma$-form. Campbell et al. [22] observed that $\gamma$-phase forms in high molecular mass iPP at high pressure over 2000 bars as well. The influence of stereo- and regio-defects was observed during the early studies. Therefore, considerable amount of $\gamma$-iPP forms during the crystallization of ethylene/ propylene random copolymers of propylene (RCPP) [23]. The results of a recent study by Krache $e t$ al. [24] supports the earlier result that the formation of $\gamma$-form is promoted by the stereo- and regiodefects in $\beta$-nucleated iPP as well. Juhász et al. [25, $26]$ studied the $\gamma$-crystallization tendency of $\beta$ nucleated and non-nucleated propylene/1-pentene copolymers and they found that the amount of $\gamma$-form increases with increasing of 1-pentene content. Moreover, the $\gamma$-crystallization tendency of 1-pentene copolymers was even higher than that of samples containing ethylene or butylene comonomer units. The structural features of $\gamma$-iPP was studied by Lotz and his co-workers [2]. They found that $\gamma$ - modification forms within the $\alpha$-phase on the lateral surface of $\alpha$-iPP crystallites $(\alpha-\gamma$ lamellar branching).

The crystallization tendency and polymorphic composition of low molecular mass iPP and its $\beta$-nucleated forms are reported in this study. Our goal was to explore the effect of changing the molecular mass in broad range on the crystallization tendency and the polymorphic composition of iPP.

\section{Experimental part}

\subsection{Materials and sample preparation}

A commercial iPP homopolymer with low molecular mass (Licowax PP 230) produced by Clariant and its $\beta$-nucleated form was used in the first series of our study. Licowax PP 230 (LICO) is often applied as lubricant and processing aid for high molecular mass iPP grades. The melt viscosity of LICO is very low $\left(\eta=1700 \mathrm{mPas}\right.$ at $\left.170^{\circ} \mathrm{C}\right)$ indicating low molecular mass.

In order to characterise the effect of molecular mass in broad range on the crystallization behaviour of iPP, peroxide degraded samples were produced from TIPPLEN H-804 neat iPP homopolymer powder $\left(\right.$ MFR $=0.2 \mathrm{~g} / 10 \mathrm{~min}$ at $230^{\circ} \mathrm{C}, 2.16 \mathrm{~kg}$ of load) supplied by TVK according to the method of controlled rheology (CR) [19, 27, 28]. During CR processing different amounts of dicumyl-peroxide (Trigonox 101) were introduced into the iPP using a Henschel FM/A10 fluid mixer at $700 \mathrm{~min}^{-1}$ of rotating speed for $5 \mathrm{~min}$. The samples were processed in a Brabender DSK 42/7 type compounder driven by a Brabender Plasti-Corder PLE 3000 unit. The temperature zones of the compounder were set to $190,200,220,220^{\circ} \mathrm{C}$ respectively. After the CR processing the MFR of the samples were measured by CEAST Modul 7027 type equipment at $230^{\circ} \mathrm{C}$ with load of $2.16 \mathrm{~kg}$. The complete decomposition of dicumyl-peroxyde was controlled by repeated measurements of MFR at $230^{\circ} \mathrm{C}$. If the secondly measured MFR value was identical with the first one, we assume that all peroxide was reacted. All samples produced by CRprocessing and their designations are included in Table 1. The non-degraded reference material with high molecular mass is $\mathrm{H}-804$, which is designated as $\mathrm{CR}-0$ in the followings.

The molecular mass and its distribution were characterized by gel permeation chromatography 
Table 1. The designation of studied non-nucleated and $\beta$-nucleated samples processed by controlled rheology

\begin{tabular}{|l|c|c|c|}
\hline $\begin{array}{l}\text { Designation } \\
\text { of samples }\end{array}$ & $\begin{array}{c}\text { Trigonox 101 } \\
\text { [ppm] }\end{array}$ & $\begin{array}{c}\text { MFR } \\
\text { [g/10 min }]\end{array}$ & Polydispersity \\
\hline $\begin{array}{l}\text { CR-0 } \\
\beta-C R-0\end{array}$ & 0 & 0.20 & 1.83 \\
\hline $\begin{array}{l}\text { CR-200 } \\
\beta-C R-200\end{array}$ & 200 & 2.64 & 3.08 \\
\hline $\begin{array}{l}\text { CR-300 } \\
\beta-C R-300\end{array}$ & 300 & 4.26 & 2.14 \\
\hline $\begin{array}{l}\text { CR-500 } \\
\beta-C R-500\end{array}$ & 500 & 11.98 & 1.99 \\
\hline $\begin{array}{l}\text { CR-800 } \\
\beta-C R-800\end{array}$ & 800 & 21.14 & 2.28 \\
\hline $\begin{array}{l}\text { CR-1000 } \\
\beta-C R-1000\end{array}$ & 1000 & 22.67 & 2.16 \\
\hline $\begin{array}{l}\text { CR-1200 } \\
\beta-C R-1200\end{array}$ & 1200 & 35.31 & 2.16 \\
\hline $\begin{array}{l}\text { CR-1600 } \\
\beta-C R-1600\end{array}$ & 1600 & 89.08 & 2.37 \\
\hline
\end{tabular}

(GPC) as well. GPC measurements were carried out using a PL-GPC 210 (Polymer Laboratories Ltd.) equipment according to ISO 16014 standard procedure. The samples were dissolved in $1,2,4-$ trichloro-benzene (TCB) $(1 \mathrm{mg} / \mathrm{ml})$ at $160^{\circ} \mathrm{C}$ for 2 hours and stabilized by 2,6-di-tert-butyl-4methylphenol (BHT) $(100 \mathrm{mg} / \mathrm{l})$.

$1000 \mathrm{ppm}$ of Irganox 1010 as stabilizer and $500 \mathrm{ppm}$ of Ca-stearate as acid scavenger were added to samples processed by CR technology, in order to avoid the further degradation. The calcium salt of suberic acid (Ca-sub), which is a highly efficient and selective $\beta$-nucleating agent, was added in $1000 \mathrm{ppm}$ to all $\beta$-nucleated blends [11]. The homogenisation of the other additives - like stabilizers, acid scavenger and $\beta$-nucleating agent in the case of $\beta$-nucleated samples - after CR processing was carried out using a Brabender W50-EH internal mixer at $220^{\circ} \mathrm{C}$ for $5 \mathrm{~min}$.

Square shaped plaques $(40 \times 40 \mathrm{~mm})$ with $1 \mathrm{~mm}$ of thickness were produced using a Fontijne hydraulic compression-moulding machine at $2.5 \mathrm{MPa}$ of pressure. The polymer was melted at $220^{\circ} \mathrm{C}$ for $2 \mathrm{~min}$ and cooled down to room temperature slowly or rapidly under constant $2.5 \mathrm{MPa}$ of pressure. In the case of slow cooling the heating of the compression moulding machine was switched off and the mould was cooled spontaneously down to room temperature with a cooling rate of $100^{\circ} \mathrm{C} / \mathrm{h}$ approximately. The rapid cooling means that the mould was cooled by cold water, which results in a cooling rate of $100^{\circ} \mathrm{C} / \mathrm{min}$ approximately.

\subsection{Experimental techniques and methods}

The structure was investigated by polarised light microscopy (PLM) and by wide angle X-ray scattering (WAXS) techniques. The PLM experiments were carried out using a Zeiss Axioscope microscope equipped by a Leica DFC 320 digital camera. In order to determine of the optical characteristics of the samples studied, a $\lambda$-plate was located diagonally between the crossed polarisers. The temperature of the samples was regulated by a Mettler FP 82 HT hot stage. The samples were crystallized under isothermal conditions after the elimination of thermal and mechanical prehistory by holding the samples at $T=220^{\circ} \mathrm{C}$ for $5 \mathrm{~min}$. The samples were cooled to the crystallization temperature $\left(T_{c}\right)$ at a cooling rate of $5^{\circ} \mathrm{C} / \mathrm{min}$. X-ray scattering patterns were recorded using a Philips PW 1830/PW type equipment with $\mathrm{CuK}_{\alpha}$ radiation at $40 \mathrm{kV}$ and $35 \mathrm{~mA}$ and X Pert PRO MPD type equipment with $\mathrm{CuK}_{\alpha}$ radiation at $40 \mathrm{kV}$ and $30 \mathrm{~mA}$. The $k$ value introduced by Turner Jones et al. [29] for characterisation of the $\beta$-content was calculated on the basis of the WAXS patterns.

The melting and crystallization characteristics of the samples were studied by calorimetric (DSC) method. The thermal and mechanical prehistory was erased by holding the samples for $5 \mathrm{~min}$ at $220^{\circ} \mathrm{C}$. Subsequently, the sample was cooled down to room temperature at a cooling rate of $10^{\circ} \mathrm{C} / \mathrm{min}$ and the crystallization curves were recorded. The melting curves were obtained during heating from room temperature to $220^{\circ} \mathrm{C}$ with a heating rate of $10^{\circ} \mathrm{C} / \mathrm{min}$. During heating of the $\beta$-nucleated samples cooled down to room temperature, $\beta \alpha$-recrystallization occurs that results in pronounced peak multiplication [30]. In order to eliminate the disturbing effect of $\beta \alpha$-recrystallization, the end temperature of recooling $\left(T_{R}\right)$ was set to $T_{R}=100^{\circ} \mathrm{C}$ in the subsequent series of the experiment (second run). According to the melting memory effect of $\beta$-iPP discussed in detail in the literature $[3,4,30]$, $\beta \alpha$-recrystallization does not appear during heating of the samples started from the critical temperature of $T_{R}^{*}=100^{\circ} \mathrm{C}$. The $\beta$-content $\left(\beta_{c}\right)$ can be estimated exactly from the melting curve of samples registered after limited recooling step [3-5]. The structural stability of the crystals are formed in LICO and $\beta$-LICO samples was characterized by melting curves recorded after cooling with different cooling rates $\left(2,5,10,20^{\circ} \mathrm{C} / \mathrm{min}\right)$. The influence of the heat- 
ing rate on the recrystallization was studied in a series of experiments using heating rates of 10, 20, 40,50 and $60^{\circ} \mathrm{C} / \mathrm{min}$.

\section{Results and discussion}

\subsection{The crystalline structure of low molecular mass iPP}

WAXS patterns of the sample LICO and its $\beta$-nucleated form are given in Figure 1. The non-nucleated LICO sample crystallizes essentially in the $\alpha$-form. The characteristic diffraction peaks corresponding to the $\alpha$-modification at $2 \theta$ of $14^{\circ}\left(\alpha_{1}(110)\right), 16.5^{\circ}$ $\left(\alpha_{2}(040)\right)$ and $18.3^{\circ}\left(\alpha_{3}(130)\right)$ respectively can be clearly seen in curve 1 of Figure 1 [17]. Predominantly $\beta$-iPP forms in the presence of the highly efficient $\beta$-nucleating agent used. The intensive diffraction peak at $2 \theta=16^{\circ}$ refers to the $\beta$-modification $\left(\beta_{1}(300)\right)$. However, a minor amount of $\alpha$-iPP is still present in the $\beta$-LICO sample (Figure 1 curve 2). The $k$-value of $\beta$-LICO sample is 0.81 . In

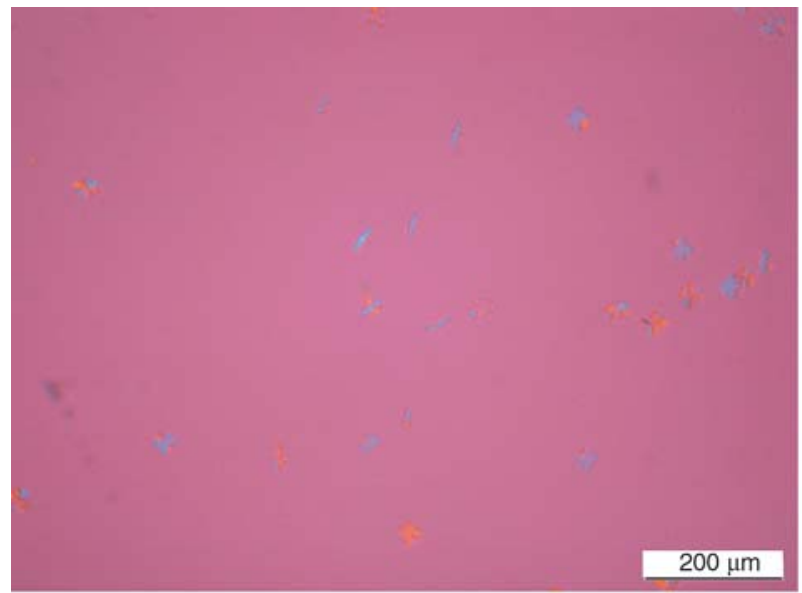

a)

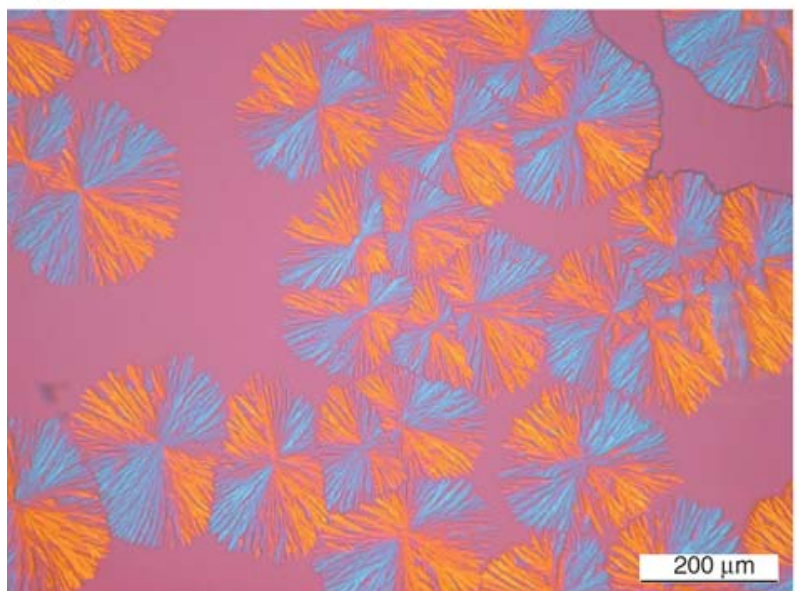

c)

Figure 2. Supermolecular structure formed during isothermal crystallization of non-nucleated LICO sample at $T_{c}=130^{\circ} \mathrm{C}$ a) $t_{c}=5 \mathrm{~min}$, b) $t_{c}=15 \mathrm{~min}$, c) $\left.t_{c}=45 \mathrm{~min}, \mathrm{~d}\right) t_{c}=90 \mathrm{~min}$ contrary to the literature sources, which have reported that $\gamma$-modification forms in low molecular mass iPP grades [18], $\gamma$-iPP could not be detected by WAXS technique in the samples studied.

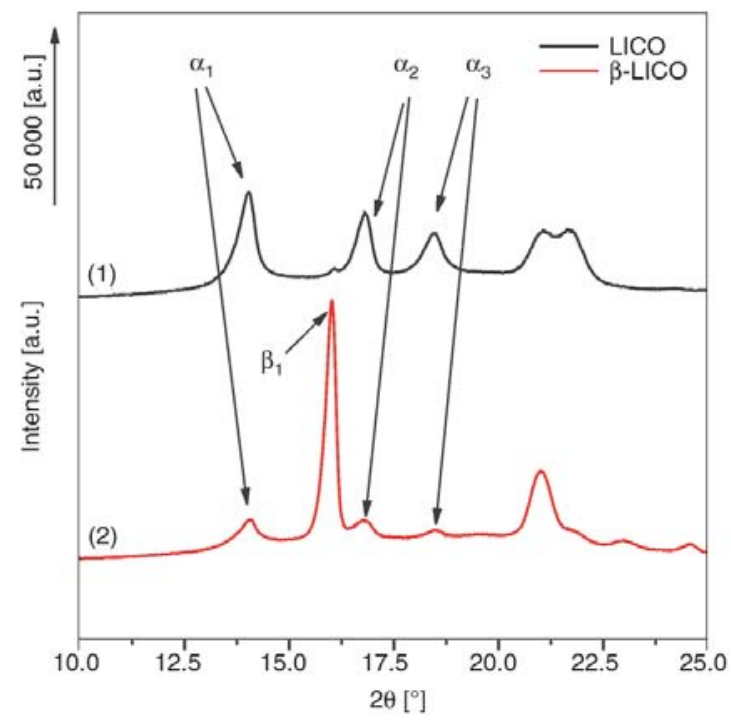

Figure 1. WAXS patterns of non-nucleated and $\beta$-nucleated LICO samples

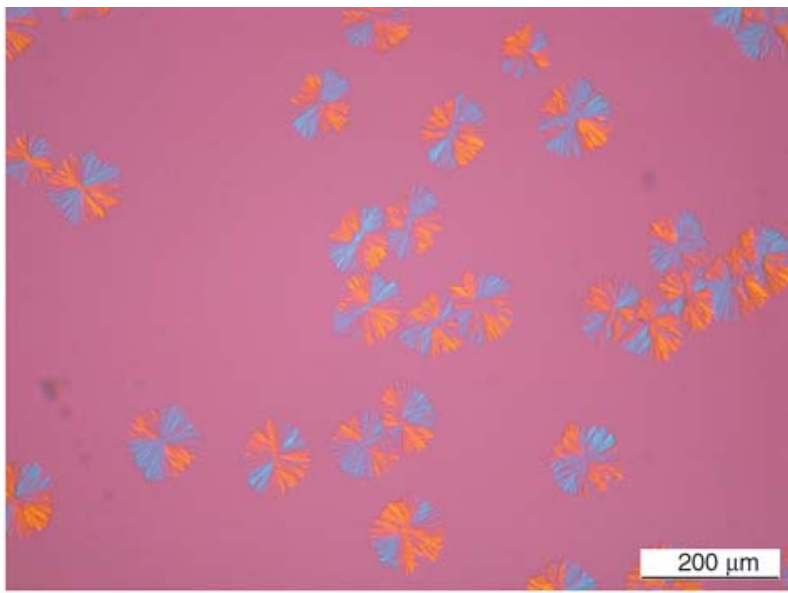

b)

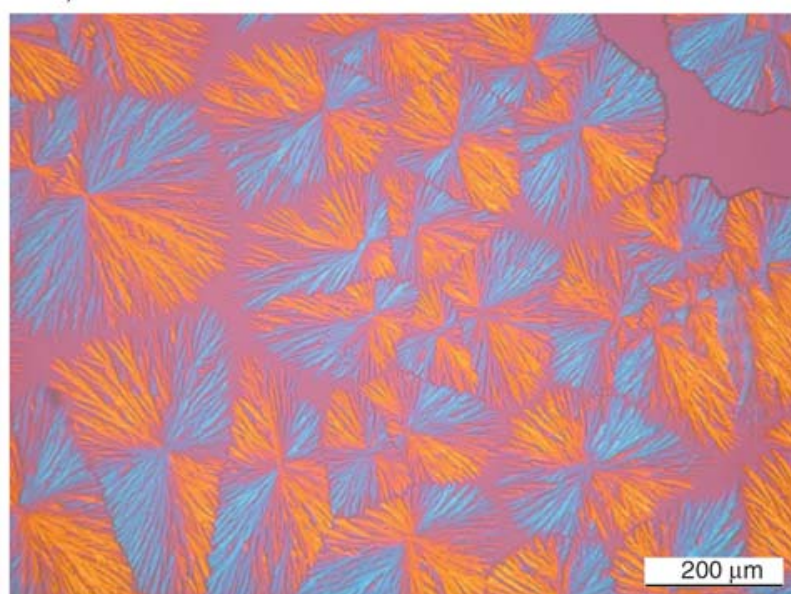

d) 
The supermolecular structure of LICO sample formed at $130^{\circ} \mathrm{C}$ is demonstrated in Figure 2. The micrographs illustrate the formation of large spherulites with positive birefringence. The lamellar branching can be observed even in PLM micrographs, indicating a more opened spherulitic structure of the low molecular mass product. In order to observe individual crystalline entities on the optical level, the $\beta$-nucleated samples were crystallized at $T_{c}=130^{\circ} \mathrm{C}$ (Figure 3). The size of the spherulites is much smaller than that in the nonnucleated sample, because of the presence of an efficient nucleating agent. The rod-like crystals with strong negative birefringence are formed in the early stage of crystallization (Figure $3 b$ ). These entities transform into $\beta$-spherulites during the latter stage of crystallization (Figure 3d). According to the former studies $[4,31]$ the rod like crystals are $\beta$-hexagonites viewed from their edge. They are the precursors of the $\beta$-spherulites.

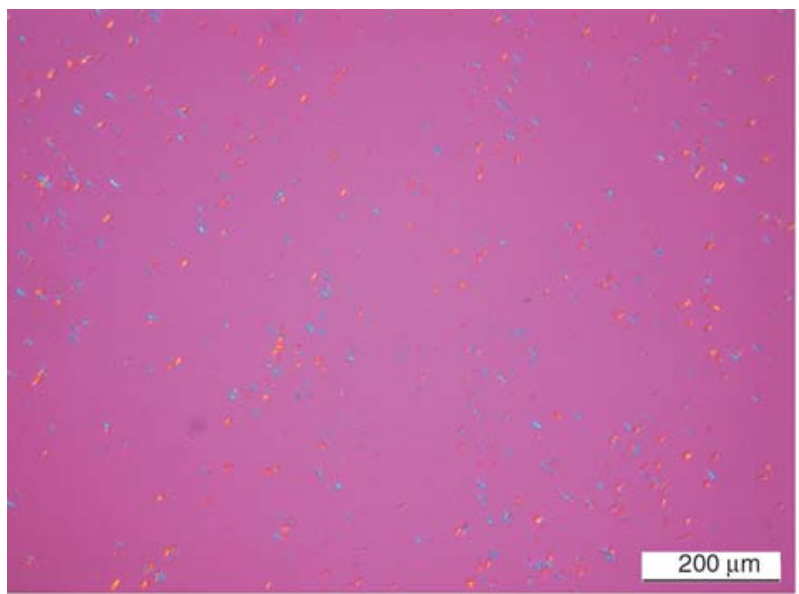

a)

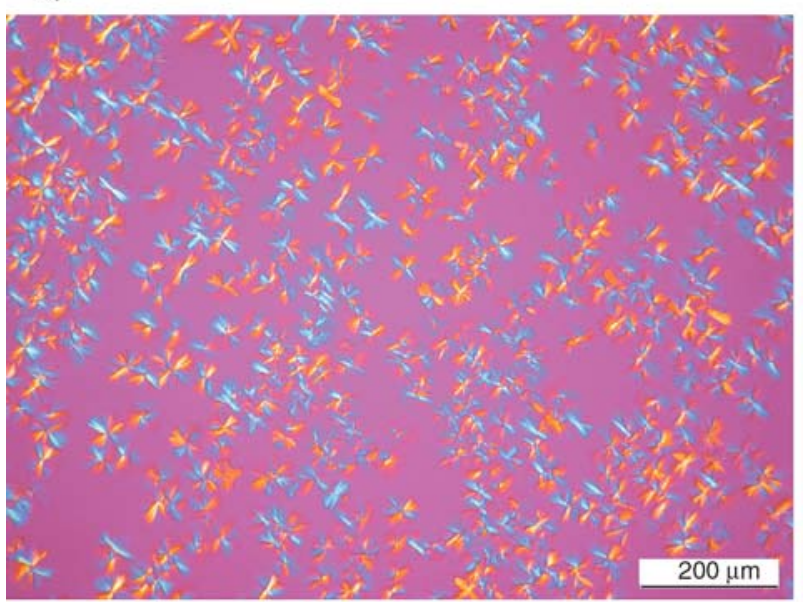

c)

\subsection{Melting and crystallization of iPP with low molecular mass}

The crystallization and melting curves of LICO and $\beta$-LICO samples and those of the CR- 0 and $\beta$-CR- 0 as a reference material are shown in Figure $4 \mathrm{a}$ and $4 \mathrm{~b}$. The peak temperature of crystallization of $\beta$ LICO $\left(T_{c p}=110.3^{\circ} \mathrm{C}\right)$ is higher than that of nonnucleated LICO samples $\left(T_{c p}=105.6^{\circ} \mathrm{C}\right)$, indicating the presence of an efficient nucleating agent. In spite of the formation of two different polymorphic phases, one peak appears in the crystallization curves of $\beta$-nucleated samples [4, 5]. Accordingly, the $\alpha$ - and the $\beta$-modifications crystallize simultaneously. On the other hand, $T_{c p}$ of LICO and $\beta$ LICO is lower than that of non-nucleated and $\beta$ nucleated reference material (CR-0 and $\beta-\mathrm{CR}-0$ ) with high molecular weight $\left(T_{c p}=111.8\right.$ and $119.1^{\circ} \mathrm{C}$ respectively).

The melting curves of low molecular mass samples are complex. The multiplied melting peaks indicate

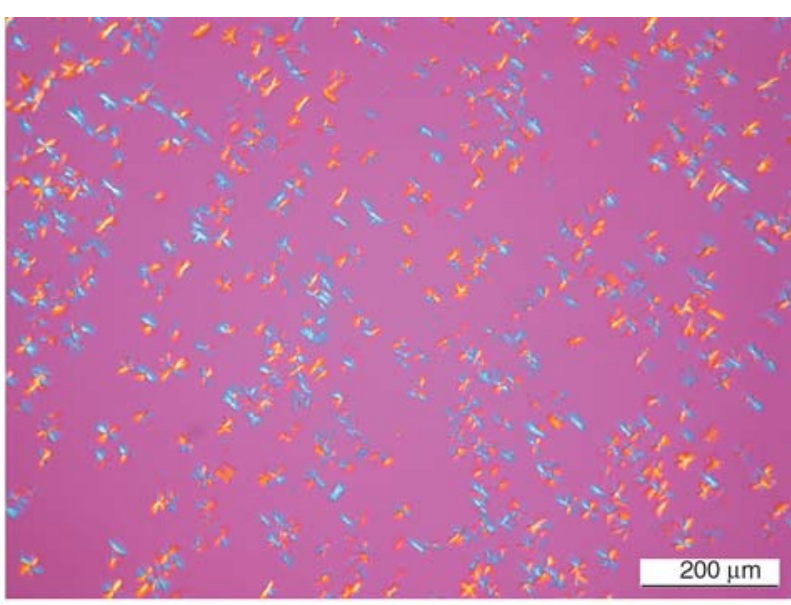

b)

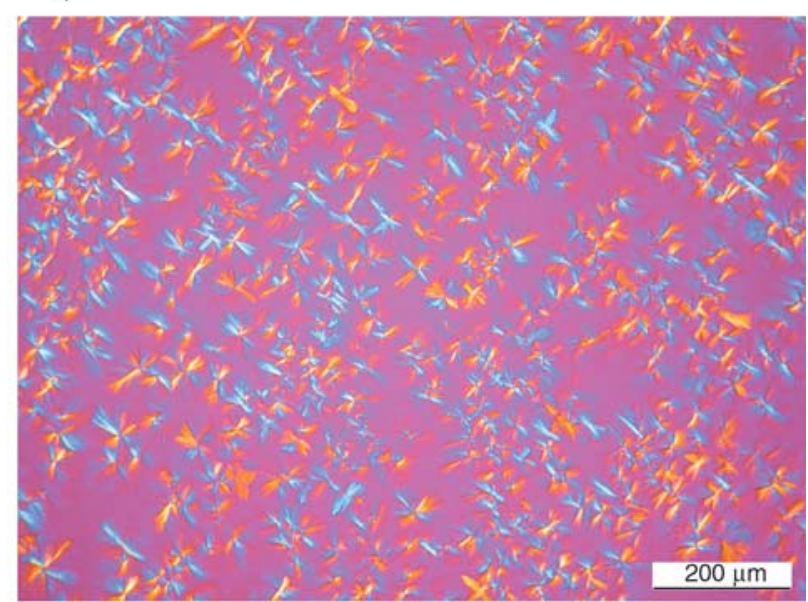

d)

Figure 3. Supermolecular structure formed during isothermal crystallization of $\beta$-nucleated LICO sample at $T_{c}=130^{\circ} \mathrm{C}$ a) $\left.\left.\left.t_{c}=1 \mathrm{~min}, \mathrm{~b}\right) t_{c}=3 \mathrm{~min}, \mathrm{c}\right) t_{c}=6 \mathrm{~min}, \mathrm{~d}\right) t_{c}=12 \mathrm{~min}$ 
several processes taking places in the samples during heating. The doubled melting of LICO in temperature range $145-155^{\circ} \mathrm{C}$ corresponds to the melting of the $\alpha$-modification (Figure $4 \mathrm{~b}$ curve 1 ). The pronounced double melting peak of the nonrecooled $\beta$-LICO sample at 135 and $140^{\circ} \mathrm{C}$ relates to melting of the $\beta$-modification (Figure $4 \mathrm{~b}$, curve 2). Moreover, a small melting peak of the $\alpha$ modification is discernible on the melting curve of the latter. According to the melting memory effect of $\beta$-iPP [30], $\beta$-LICO sample cooled below $T_{R}^{*}$ recrystallizes in to the $\alpha$-form during the partial melting of unstable $\beta$-phase ( $\beta \alpha$-recrystallization) resulting in multiplied melting curves (Figure $4 b$, curve 3 ) and in the appearance of a large $\alpha$-melting peak. The temperature range of the melting of the $\beta$-LICO is lower than that of $\alpha$-LICO (Figure $4 b$ ), because of the lower thermodynamical stability of the $\beta$-form. Since the melting temperature of high molecular mass $\alpha$ - and $\beta$-form is at about 166 and $155^{\circ} \mathrm{C}$ respectively, the lower molecular mass results in a decreased melting temperature for both modifications. The lower melting temperature of low molecular mass material is connected with a higher density of the chain ends incorporated in the crystal lattice, which leads to the formation of crys-

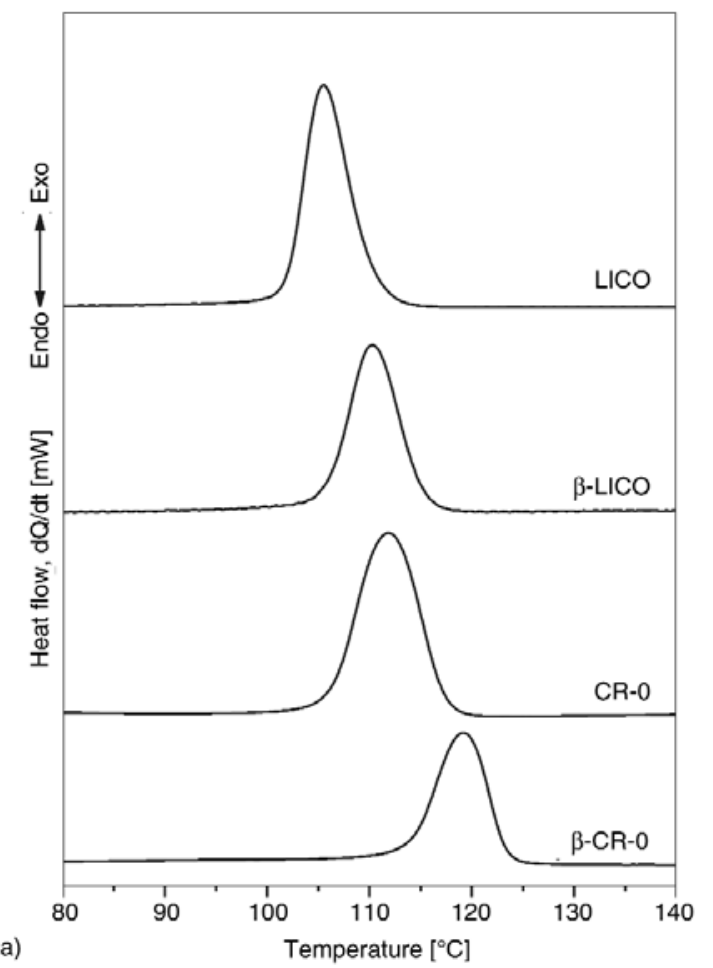

tal defects, consequently less perfect structure with lower structural stability. The melting peak duplication of the $\alpha$ - and $\beta$-modification (Figure $4 \mathrm{~b}$ ) can be explained by structural instability as well. The peak duplication resulted in the superposition of the endothermic perfection process (recrystallization) on the exothermic partial melting of the unstable crystal structure. Accordingly, the lower peak temperature ( $\alpha$ and $\beta$ ) corresponds to the temperature, where the rate of the melting and recrystallization are identical [3, 4]. Consequently, the peaks at lower temperatures are not real, but apparent melting peak temperatures. The higher peak temperature $\left(\alpha^{\prime}\right.$ and $\left.\beta^{\prime}\right)$ indicates the melting of crystalline fraction formed during the recrystallization within the same phase ( $\alpha \alpha^{\prime}$ - and $\beta \beta^{\prime}$-recrystallization) throughout heating.

The structural stability depends on the thermal condition of the crystallization. The lower the crystallization temperature is, the higher is the structural instability. In a series of experiment, samples of low molecular mass iPP with different structural stabilities were prepared under non-isothermal crystallization at different cooling rates. The crystallization curves of LICO and $\beta$-LICO recorded at different cooling rates are presented in Figure 5.

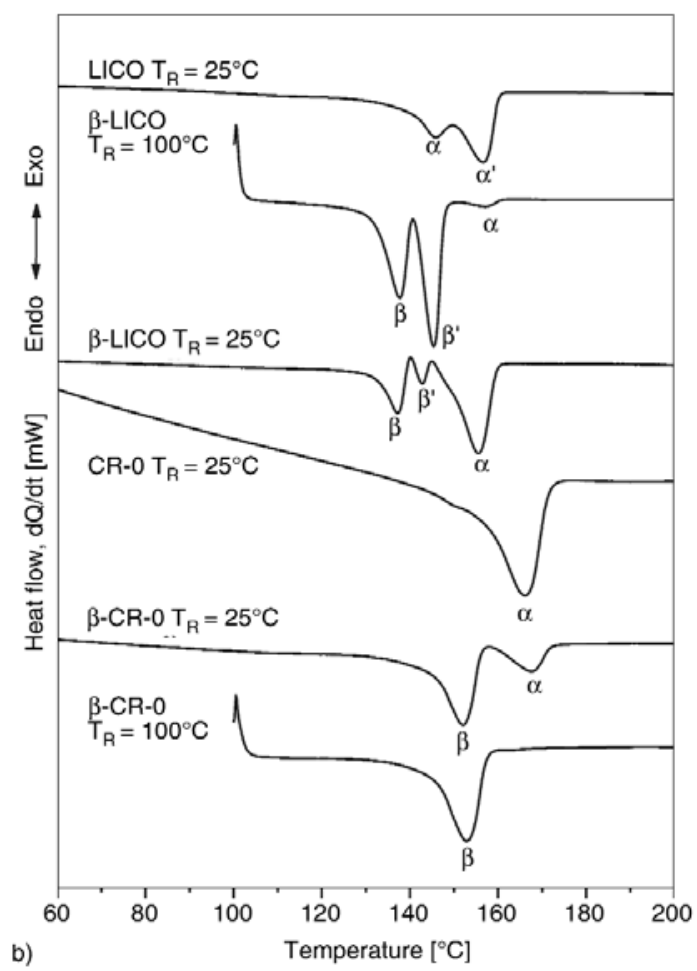

Figure 4. a) Crystallization curves of non-nucleated and $\beta$-nucleated LICO and CR-0 samples $\left(T_{R}=25^{\circ} \mathrm{C}\right)$ and b) melting curves of non-nucleated and $\beta$-nucleated LICO and CR-0 samples recorded after limited $\left(T_{R}=100^{\circ} \mathrm{C}\right)$ and nonlimited recooling $\left(T_{R}=25^{\circ} \mathrm{C}\right)$. Note: the different thermal history of the samples is indicated in the melting curves. 

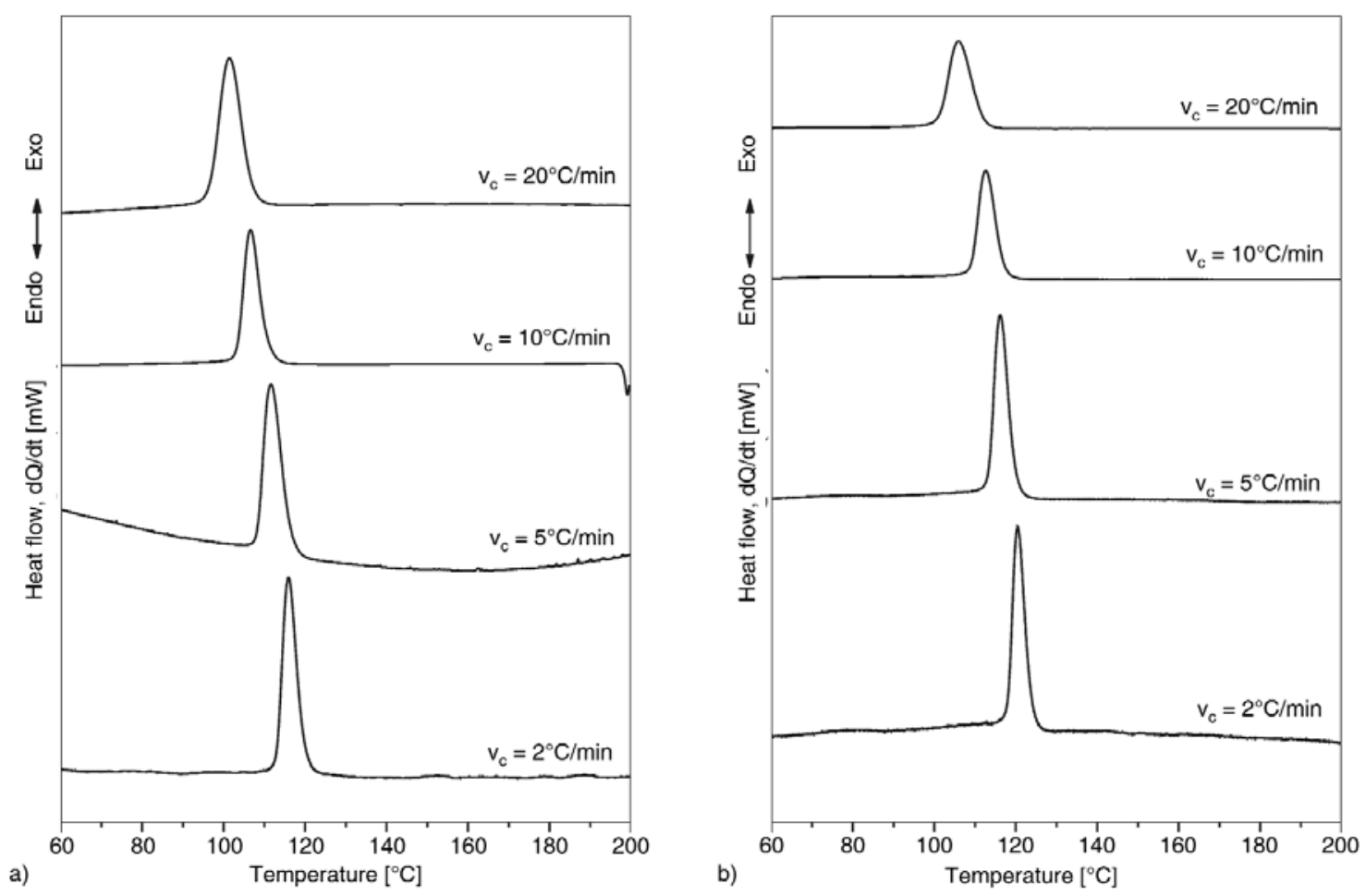

Figure 5. Crystallization curves of LICO (a) and $\beta$-LICO (b) sample registered at different cooling rate

The faster the cooling rate is, the lower is the peak temperature of crystallization and consequently the structural stability of the samples, although the $\beta$ nucleated LICO crystallizes always at higher temperature than the non-nucleated samples. The melt-

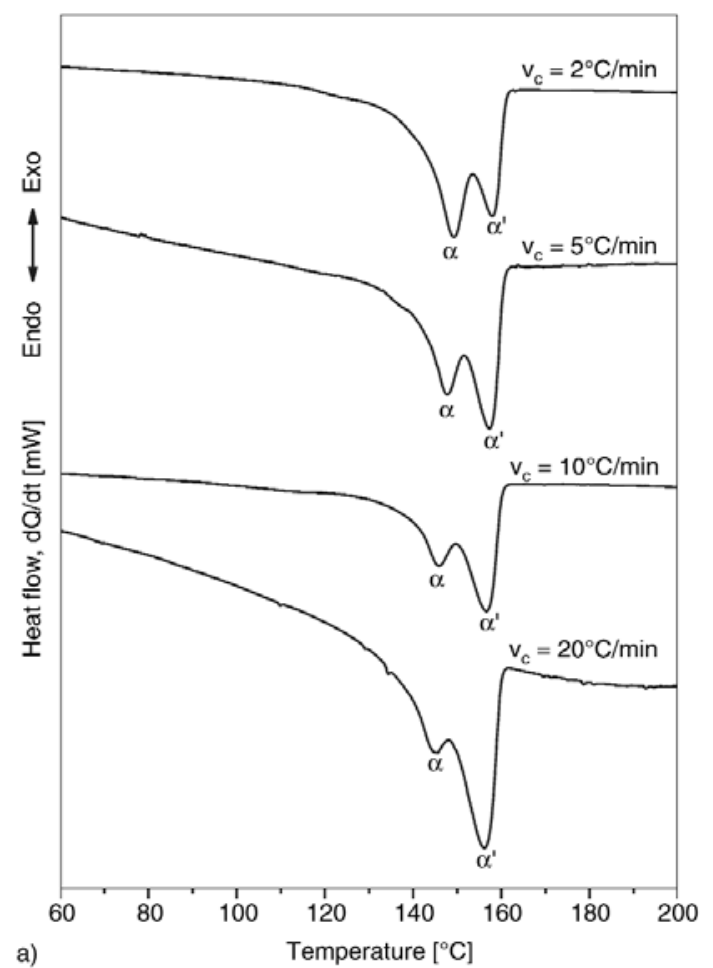

ing curves registered after cooling with different rates are given in Figure 6. It is unambiguous that the recrystallized part (intensity of peaks $\alpha^{\prime}$ and $\beta^{\prime}$ ) increases with increasing the cooling rate, confirming the higher structural instability. Simultane-

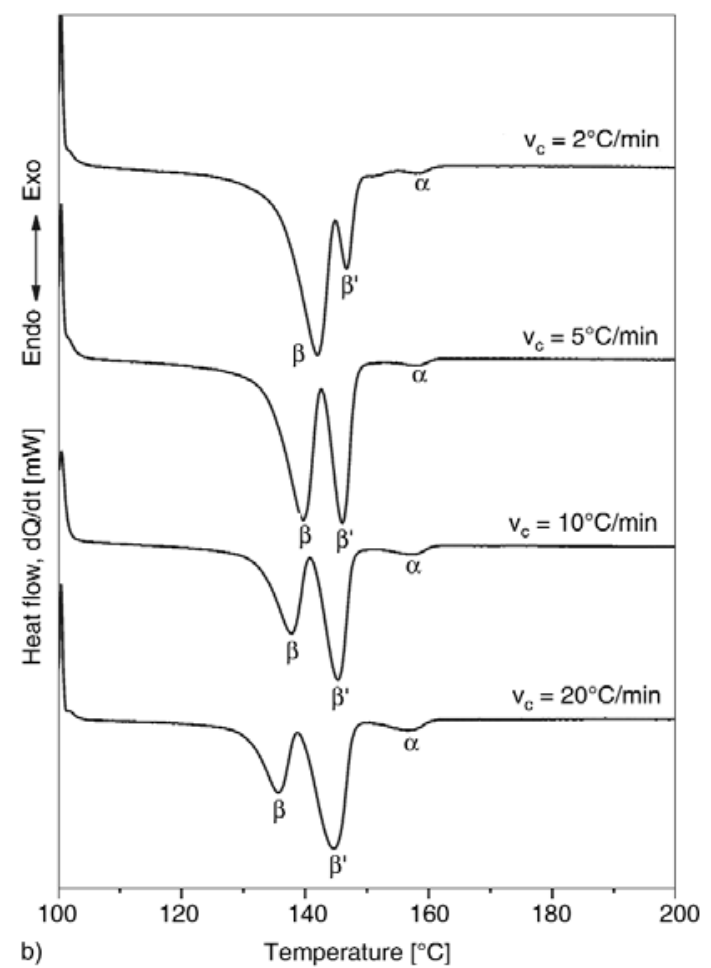

Figure 6. a) Melting curves of LICO crystallized at different cooling rate $\left(T_{R}=25^{\circ} \mathrm{C}\right)$, b) melting curves of $\beta$-LICO samples crystallized at different cooling rate $\left(T_{R}^{*}=100^{\circ} \mathrm{C}\right)$ 
ously, the apparent melting peak ( $\alpha$ and $\beta$ ) at lower temperature decreases, which confirms that the recrystallization starts at lower temperature in both modifications with increasing structural instability. Since the recrystallization is a time dependent process, the increase of the heating rate gradually surpasses the recrystallization during heating and consequently the peak duplication becomes less pronounced. This statement is proved by the melting curves presented in Figure $7 \mathrm{a}$ and $7 \mathrm{~b}$, where the influence of the heating rate on the melting profile of LICO and $\beta$-LICO is shown. It is well seen that the peak duplication at the highest heating rates (above $50^{\circ} \mathrm{C} / \mathrm{min}$ ) is almost disappears, i.e. the recrystallization is negligible. The melting peak temperature recorded with heating rate of $50^{\circ} \mathrm{C} / \mathrm{min}$ $\left(T_{m p}=152.7^{\circ} \mathrm{C}\right)$ can be accepted as $T_{m p}$ of crystalline fraction formed originally, because the disturbing effect of the $\alpha \alpha^{\prime}$-recrystallization was practically eliminated. It worth mentioning that the inclination to the crystallisation can be approximately characterized by the apparent undercoolability, i.e. by the difference of melting and crystallization peak temperature $\left(\Delta T=T_{m p}-T_{c p}\right)$. Based on the calorimetric data the undercoolability of non-nucleated and $\beta$-nucleated LICO and CR samples is summarized in Table 2. The $\Delta T$ value for non-nucleated samples is little lower than of $50^{\circ} \mathrm{C}$. $\Delta T$ decreases monotonously with decreasing molecular mass. The lower undercoolability (the higher

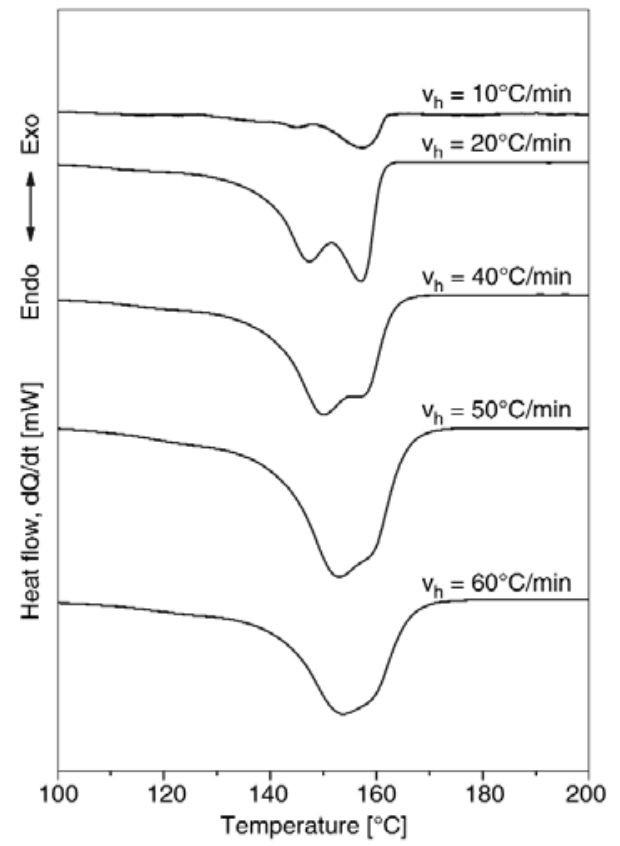

inclination for crystallization) of LICO is a consequence of higher chain mobility and lower melt viscosity. The $\beta$-nucleated samples have significantly lower $\Delta T$, because of the presence of a highly efficient nucleating agent, but $\Delta T$ decreases with decreasing molecular mass similarly to the nonnucleated samples. The results obtained by the variation of the cooling and heating rates confirmed that the explanation of the multiplication of the melting peaks is correct.

The polymorphic composition can be calculated from the melting curve registered after limited recooling $\left(T_{R}=T_{R}^{*}=100^{\circ} \mathrm{C}\right)$. The $\beta$-content $\left(\beta_{c}\right)$ estimated from the melting curve recorded after limited recooling is $97 \%$. The $\beta_{c}$ of the $\beta$-CR-0 is higher $\left(\beta_{c}>99 \%\right)$ than that of $\beta$-LICO, signifying

Table 2. The crystallization $\left(T_{c p},\right)$ melting peak temperatures $\left(T_{m p}\right)$ and the undercoolability $(\Delta T)$ of nonnucleated and $\beta$-nucleated CR and LICO samples crystallized using $10^{\circ} \mathrm{C} / \mathrm{min}$ of cooling and melted with $50^{\circ} \mathrm{C} / \mathrm{min}$ of heating rate

\begin{tabular}{|l|c|c|c|c|c|c|}
\hline \multirow{2}{*}{$\begin{array}{c}\text { Sample } \\
\text { name }\end{array}$} & \multicolumn{3}{|c|}{$\boldsymbol{\beta}$-nucleated } & \multicolumn{3}{c|}{ Non-nucleated } \\
\cline { 2 - 7 } & $\mathbf{T}_{\mathbf{c p}}$ & $\mathbf{T}_{\mathbf{m p}}$ & $\boldsymbol{\Delta} \mathbf{T}$ & $\mathbf{T}_{\mathbf{c p}}$ & $\mathbf{T}_{\mathbf{m p}}$ & $\boldsymbol{\Delta} \mathbf{T}$ \\
\hline CR-0 & 119.5 & 154.3 & 34.9 & 113.3 & 162.7 & 49.4 \\
\hline CR-200 & 120.0 & 154.3 & 34.4 & 114.1 & 162.7 & 48.5 \\
\hline CR-300 & 119.3 & 152.7 & 33.4 & 111.6 & 162.7 & 51.0 \\
\hline CR-500 & 120.3 & 152.7 & 32.4 & 114.8 & 162.7 & 47.9 \\
\hline CR-800 & 120.5 & 152.7 & 32.2 & 113.1 & 162.7 & 49.5 \\
\hline CR-1000 & 120.1 & 152.7 & 32.5 & 112.1 & 161.8 & 49.7 \\
\hline CR-1200 & 120.5 & 153.5 & 33.0 & 113.1 & 161.8 & 48.7 \\
\hline CR-1600 & 120.0 & 152.7 & 32.7 & 115.1 & 162.7 & 47.5 \\
\hline Licowax & 110.3 & 142.7 & 32.4 & 105.5 & 152.7 & 47.2 \\
\hline
\end{tabular}

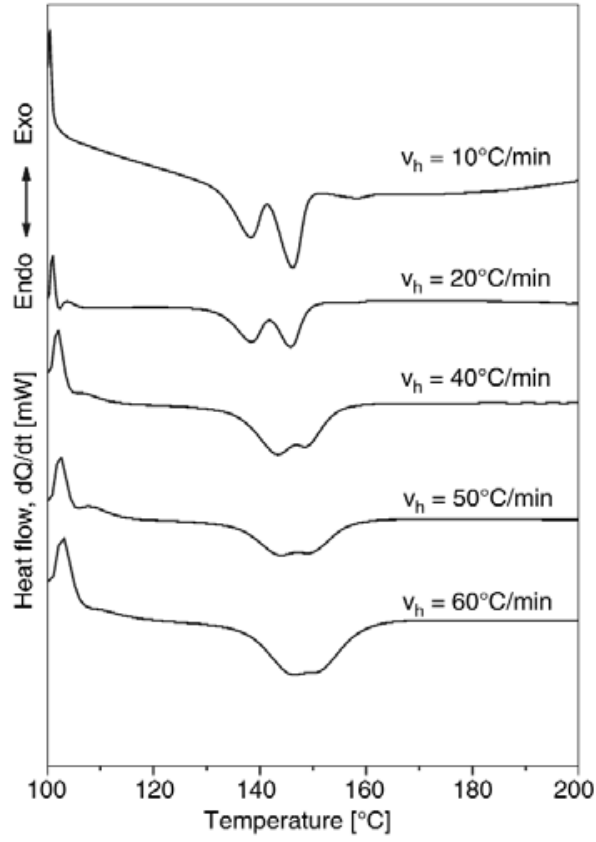

Figure 7. Melting curves of non-nucleated (a) and $\beta$-nucleated (b) LICO samples recorded with different heating rates 
the reduced $\beta$-crystallization tendency of low molecular mass iPP.

\subsection{Crystalline structure of peroxide- degraded samples}

In order to determine the influence on the molecular mass on the structural stability and the inclination for recrystallization, iPP samples with different molecular masses and MFR were prepared by controlled degradation process $(\mathrm{CR})$ in the presence of dicumyl-peroxide. The molecular mass and MFR range achieved by $\mathrm{CR}$ processing as a function of peroxide content are shown in Figure 8. The molecular mass of the samples is changing as a result of chain scission, which can influence the polydispersity and the regularity of the chain as well (Table 1). The WAXS patterns of non-nucleated CR samples registered on compression molded plaques are shown in Figure 9. The diffraction peaks indicate that the samples - except CR- 0 - crystallize in $\alpha$ modification in the whole MFR range. In the case of CR-0, a small peak at $2 \theta=16^{\circ}$ appears that cor-

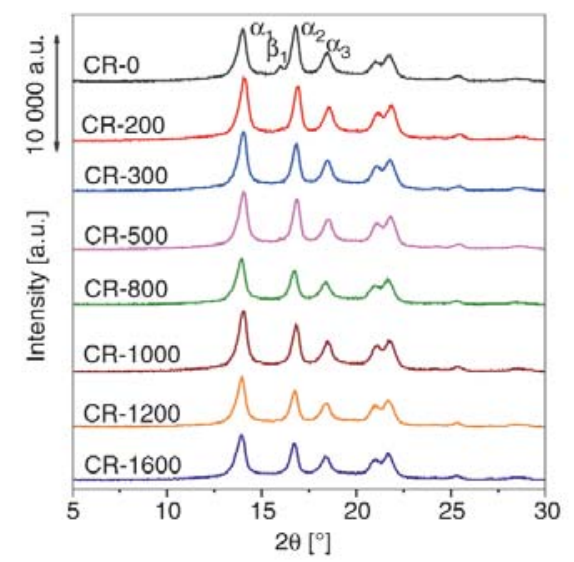

responds to traces of $\beta$-iPP. Its formation is probably induced by mechanical load on the melt during compression moulding [32]. It should be noted that the diffraction peak of $\beta$-iPP is more pronounced in the CR-0 processed with slow cooling rate (Figure $9 b$ ). The diffraction patterns of $\beta$-nucleated $C R$ samples are given in Figure 10. All samples crystallized in $\beta$-form independently of their MFR and

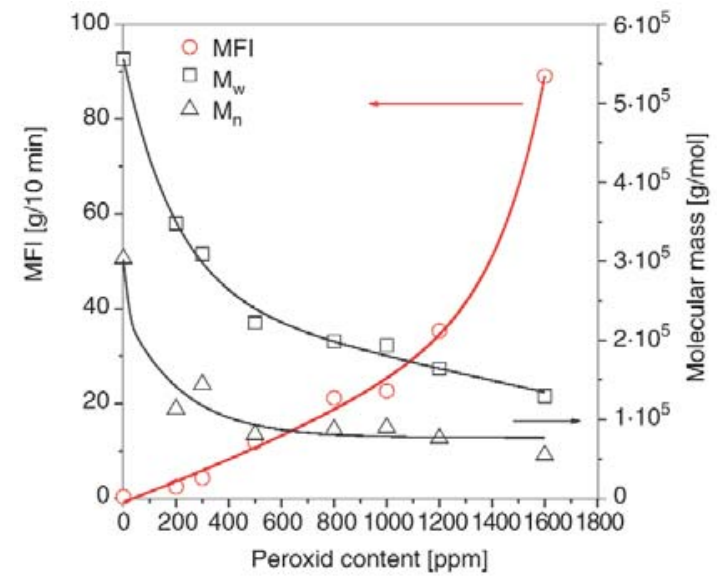

Figure 8. Dependence of the MFR and molecular weight $\left(M_{n}\right.$ and $\left.M_{w}\right)$ values of the CR samples on peroxide content

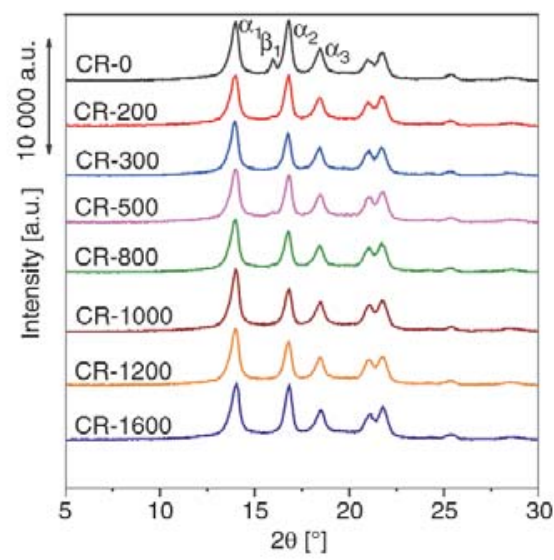

Figure 9. WAXS patterns of CR samples with different MFR processed by rapid (a) and slow (b) cooling
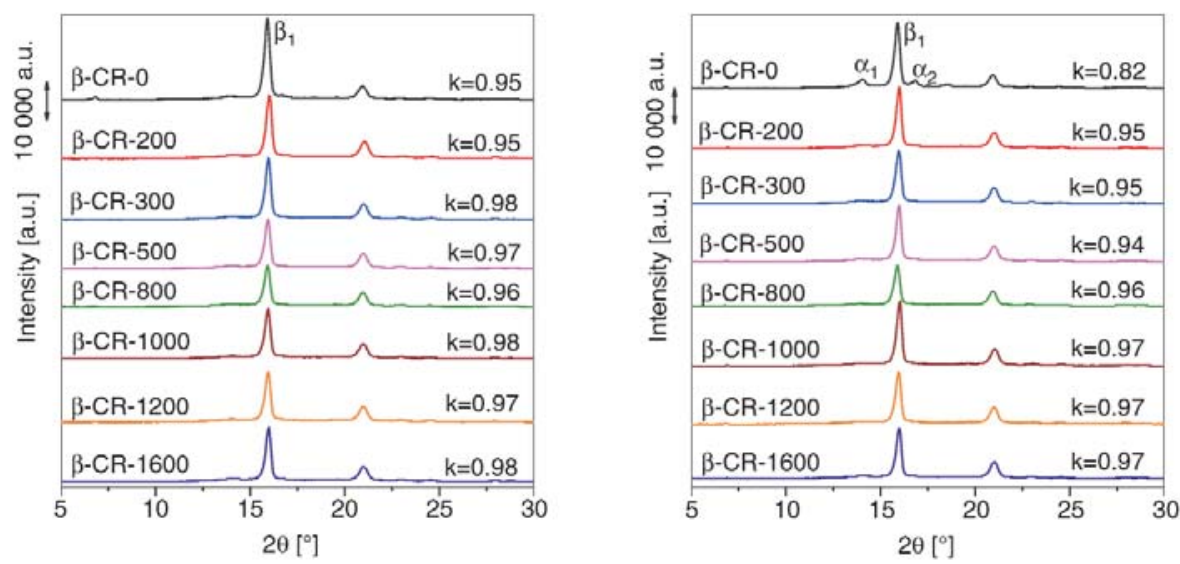

Figure 10. WAXS patterns of $\beta$-CR samples with different MFR processed by rapid (a) and slow (b) cooling 


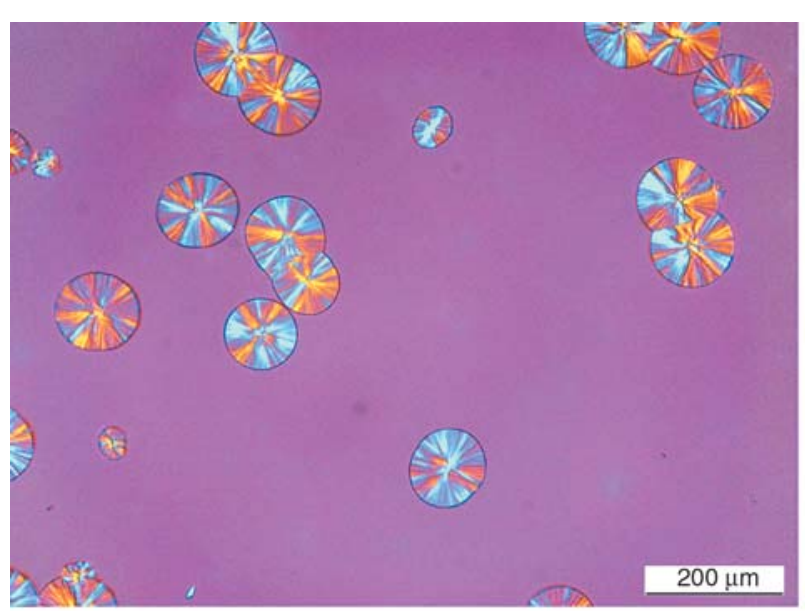

a)

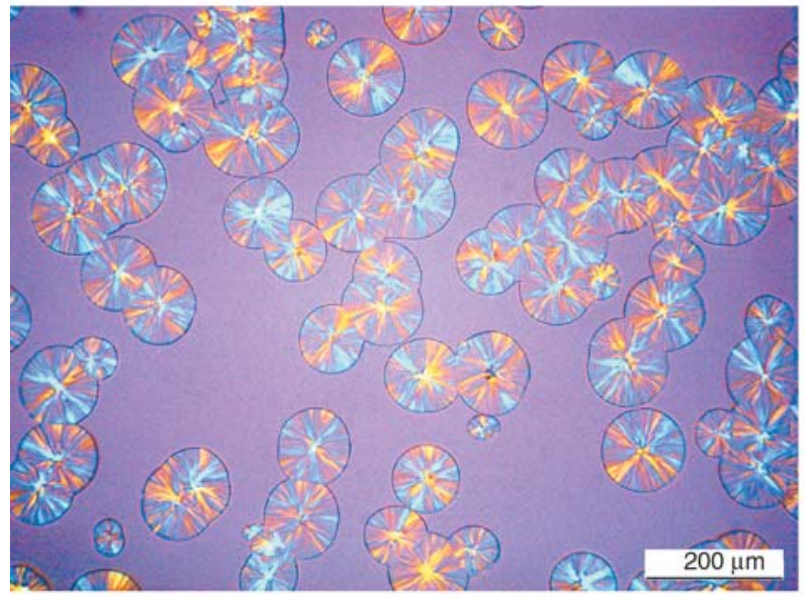

c)

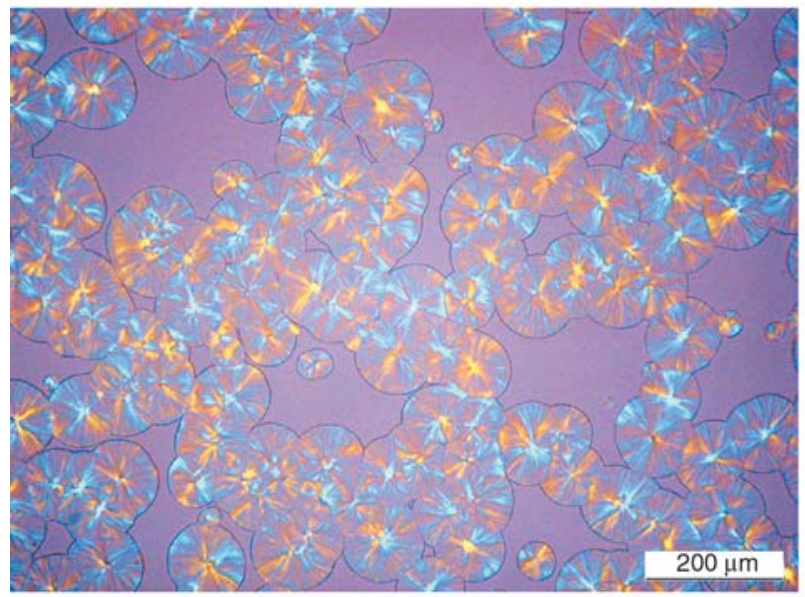

e)

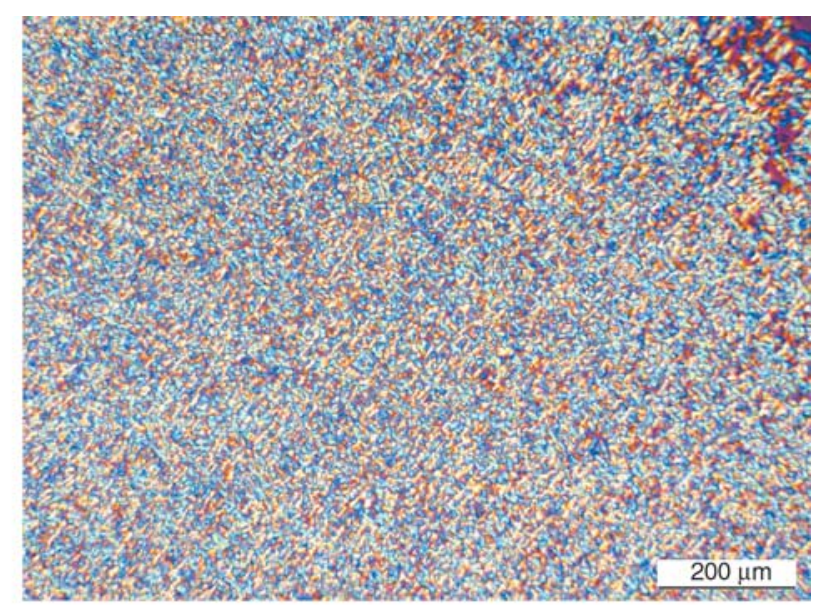

b)

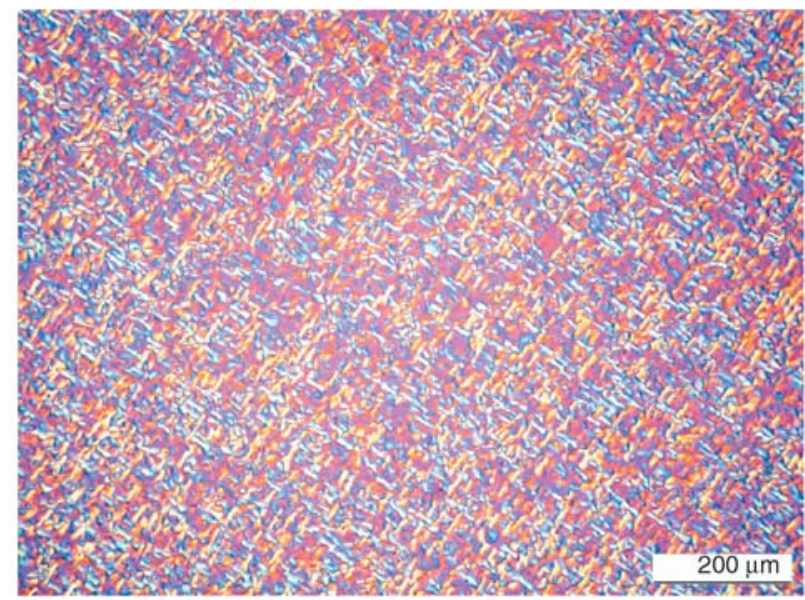

d)

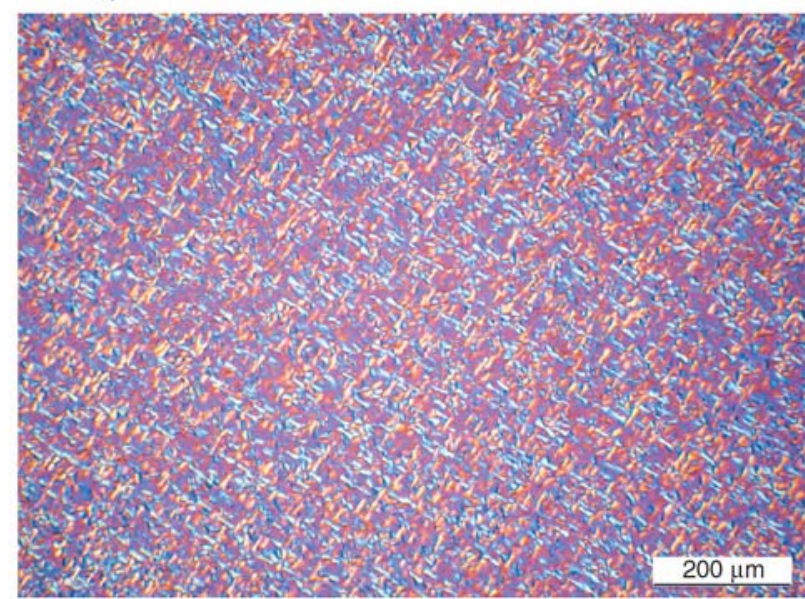

f)

Figure 11. Supermolecular structure formed during isothermal crystallization of peroxide degraded samples at $T_{c}=130^{\circ} \mathrm{C}$ a) non-nucleated CR-0, $t_{c}=10 \mathrm{~min}$; b) $\beta$-nucleated CR-0, $t_{c}=1 \mathrm{~min}$; c) non-nucleated CR-800, $t_{c}=10 \mathrm{~min}$; d) $\beta$-nucleated CR-800, $t_{c}=1.5 \mathrm{~min}$; e) non-nucleated CR-1600, $t_{c}=10 \mathrm{~min}$; f) $\beta$-nucleated CR-1600, $t_{c}=3 \mathrm{~min}$

of the cooling rate applied during compression moulding. The $k$ values are above 0.94 except the compression moulded plaque $\beta$-CR- 0 produced with slow cooling. This can be explained by the formation of $\alpha$-self nuclei in the high molecular weight sample above the upper critical temperature $\left(140^{\circ} \mathrm{C}\right)$ of the formation of the $\beta$-iPP $[3,4] . \mathrm{We}$ have to emphasize that no formation of $\gamma$-form could be detected in the samples studied. The results ascertain that neither the decreasing molecular mass, nor the degradation of iPP result in the formation of $\gamma$-form. Based on our recent results, it 
can be concluded that the stereo- and regio-defects might play dominant role in forming of $\gamma$-modification instead of low molecular mass. We suppose that iPP produced using recent superactive catalyst systems, which provide highly stereoregular structure (isotacticity is usually higher than 98\%), is not inclined to the formation of $\gamma$-form. The formation of $\gamma$-iPP observed in the pioneering works on this topic [18] might be explained by the lower stereoregularity of the earlier iPP grades.

The supermolecular structure of peroxide degraded samples is demonstrated in Figure 11. Large spherulites are formed (Figure 11a) during the crystallization of the non-degraded reference material $(\mathrm{CR}-0)$ at $T_{c}=130^{\circ} \mathrm{C}$. All non-nucleated samples crystallize essentially in $\alpha$-modification. Figure $11 \mathrm{a}, 11 \mathrm{c}$ and $11 \mathrm{e}$ demonstrate the crystalline structure formed after $10 \mathrm{~min}$ of crystallization of CR-0, CR-800 and CR-1600 samples respectively. The number of spherulites formed increases with increasing peroxide content, representing the increased molecular mobility of the peroxide degraded samples. The larger the mobility of the chains is the higher is the rate of formation of the nuclei. The presence of the $\beta$-nucleating agent promotes the formation of microspherulitic structure, which consists of $\beta$-iPP exclusively. Moreover, the crystallization of $\beta$-nucleated samples is much faster than that of the non-nucleated ones.

\subsection{Melting and crystallization characteristics of peroxide-degraded samples}

The melting curves of non-nucleated CR samples registered after limited recooling are shown in Figure 12. The quantitative thermal characteristics obtained from evaluation of the crystallization and melting curves of non-nucleated CR samples are collected in Table 3. The non-nucleated CR samples with lager MFR possess higher peak temperature (Table 2 ) of crystallization $\left(T_{c p}\right)$. These results hint at the increased chain mobility as the consequence of the decreased melt viscosity and lower entanglement density. The melting peak temperature shifts toward to lower temperatures with decreasing molecular mass. Moreover, peak duplication signifying the decreased structural stability appears above peroxide content of $800 \mathrm{ppm}(\mathrm{CR}$ 800-CR-1600). The enthalpy of fusion $\left(\Delta H_{m}\right)$

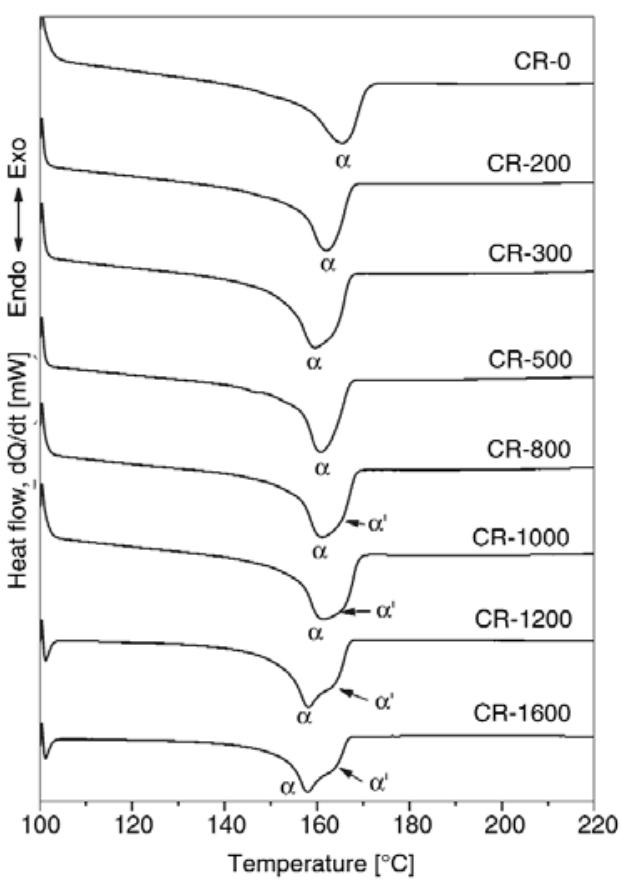

Figure 12. Melting curves of CR samples crystallized at cooling rate of $10^{\circ} \mathrm{C} / \mathrm{min}\left(T_{R}=100^{\circ} \mathrm{C}\right)$

Table 3. Thermal characteristics of non-nucleated CR samples determined on the basis of the melting and crystallization curves $\left(T_{R}=25^{\circ} \mathrm{C}\right)$

\begin{tabular}{|l|c|c|c|}
\hline \multicolumn{1}{|c|}{ Samples } & $\boldsymbol{\Delta}_{\mathbf{c}}[\mathbf{J} / \mathbf{g}]$ & $\mathbf{T}_{\mathbf{m p}}\left[{ }^{\circ} \mathbf{C}\right]$ & $\Delta \mathbf{H}_{\mathbf{m}}[\mathbf{J} / \mathbf{g}]$ \\
\hline CR-0 & 86.0 & 166.0 & 80.0 \\
\hline CR-200 & 88.0 & 162.7 & 83.4 \\
\hline CR-300 & 88.1 & 159.7 & 83.2 \\
\hline CR-500 & 90.3 & 161.7 & 85.8 \\
\hline CR-800 & 90.0 & 161.4 & 87.2 \\
\hline CR-1000 & 89.5 & $\begin{array}{c}(\alpha) 161.5 \\
\left(\alpha^{\prime}\right) 166.3\end{array}$ & 88.1 \\
\hline CR-1200 & 90.8 & $\begin{array}{c}(\alpha) 158.4 \\
\left(\alpha^{\prime}\right) 164.7\end{array}$ & 89.6 \\
\hline CR-1600 & 88.8 & $\begin{array}{c}(\alpha) 158.2 \\
\left(\alpha^{\prime}\right) 164.6\end{array}$ & 87.3 \\
\hline
\end{tabular}

$T_{m p}$ - peak temperature of melting of $\alpha$-modification, where $\alpha$ and $\alpha$ ' are the temperatures of the doubled melting peaks

increases with increasing MFR. We have to point out that this apparent increase can be caused by the more and more pronounced $\alpha \alpha^{\prime}$-recrystallization with decreasing molecular mass. The more pronounced the recrystallization is, the higher is the $\Delta H_{m}$ values.

The melting curves of the non-recooled, $\beta$-nucleated CR samples are given in Figure 13. The quantitative thermal characteristics obtained from the evaluation of crystallization and melting curves of $\beta$-nucleated CR samples are collected in Table 4. The peak temperatures of crystallization of $\beta$ nucleated samples are higher than those of the nonnucleated ones and located in the vicinity of $120^{\circ} \mathrm{C}$. 


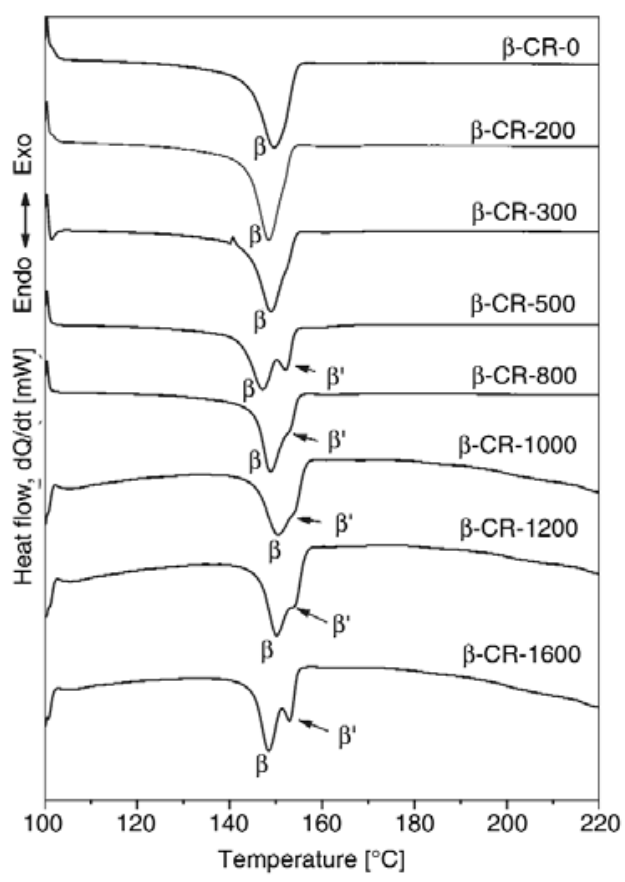

Figure 13. Melting curves $\beta$-nucleated CR crystallized at a cooling rate of $10^{\circ} \mathrm{C}\left(T_{R}=100^{\circ} \mathrm{C}\right)$

$T_{c p}$ values increase slightly with increasing MFR (Table 4). The melting peaks are located in the temperature range of $145-155^{\circ} \mathrm{C}$, which is characteristic of the $\beta$-iPP with high molecular mass. Furthermore, melting shifts toward lower temperatures with decreasing of molecular mass, similarly to the non-nucleated CR samples. The duplication of melting peak becomes visible at higher molecular mass range compared with non-nucleated samples. The pronounced peak duplication, which is caused by the $\beta \beta^{\prime}$-recrystallization of the unstable crystalline structure, can be clearly seen in $\beta$-CR$500-\beta-C R-1600$ samples (Figure 13). This obser- vation ascertains that the structural stability of $\beta$ form is smaller than that of $\alpha$-form, in spite of the fact that the $\beta$-nucleated samples are crystallized at higher temperature range (Table 3 and 4 ). The $\beta_{c}$ values are higher than $98 \%$ in most of $\beta$-nucleated CR samples.

The melting curves of $\beta$-nucleated samples cooled to room temperature are shown in Figure 14. The melting profiles reflect that $\beta \alpha$-recrystallization takes place during heating according to former observations $[3,4,30]$. It seems that increasing number of crystal defects caused by the chain ends included in the crystal lattice with decreasing of molecular mass promote the $\beta \alpha$-recrystallization as well. Therefore, the $\beta \alpha$-recrystallization overlaps with and suppresses the $\beta \beta^{\prime}$-recrystallization. The melting peak duplication hinting at the $\beta \beta^{\prime}$-recrystallization within the $\beta$-form appears only in the case of $\beta$-CR-1600 sample as an indistinct shoulder on the melting cure.

We have to call the attention to the fact once again that $\beta \alpha$-recrystallization superimposed on the partial melting of the $\beta$-phase during heating of the samples cooled down to room temperature influences the melting profile considerably. Therefore, melting peak temperatures and enthalpy of fusion determined from the melting curves recorded during heating from room temperature are apparent values. Consequently, the melting curves of recooled samples do not provide exact information about $\beta_{c}$. Indeed, the $\beta_{c}$ values determined from melting curves of samples heated from room temperature are much lower than those obtained from

Table 4. Thermal characteristics of $\beta$-nucleated CR samples determined on the basis of the melting and crystallization curves

\begin{tabular}{|c|c|c|c|c|c|c|}
\hline \multirow[t]{2}{*}{ Samples } & \multicolumn{3}{|c|}{$\begin{array}{l}\text { Heating after limited recooling } \\
\qquad\left(\mathbf{T}_{R}=100^{\circ} \mathrm{C}\right)\end{array}$} & \multicolumn{3}{|c|}{$\begin{array}{l}\text { Cooling to room temperature and subsequent heating } \\
\qquad\left(\mathrm{T}_{\mathrm{R}}=25^{\circ} \mathrm{C}\right)\end{array}$} \\
\hline & $\mathbf{T}_{\mathbf{m p}}\left[{ }^{\circ} \mathbf{C}\right]$ & $\Delta \mathbf{H}_{\mathrm{m}}[\mathrm{J} / \mathrm{g}]$ & $\beta_{c}[\%]$ & $\Delta \mathbf{H}_{\mathrm{c}}[\mathrm{J} / \mathrm{g}]$ & $\Delta \mathbf{H}_{\mathrm{m}}[\mathbf{J} / \mathbf{g}]$ & $\beta_{c}[\%]$ \\
\hline$\beta-\mathrm{CR}-0$ & 149.7 & 82.2 & 98.8 & 85.4 & 95.1 & 78.7 \\
\hline$\beta-\mathrm{CR}-200$ & 148.5 & 81.5 & 98.5 & 85.7 & 94.0 & 79.0 \\
\hline$\beta-C R-300$ & 149.0 & 86.2 & 98.3 & 81.2 & 88.5 & 76.8 \\
\hline$\beta-\mathrm{CR}-500$ & $\begin{array}{l}(\beta) 147.2 \\
\left(\beta^{\prime}\right) 152.2\end{array}$ & 86.0 & 96.8 & 82.5 & 85.8 & 73.1 \\
\hline$\beta-\mathrm{CR}-800$ & $\begin{array}{l}(\beta) 148.9 \\
\left(\beta^{\prime}\right) 153.0\end{array}$ & 88.7 & 98.2 & 84.6 & 87.3 & 77.9 \\
\hline$\beta-C R-1000$ & $\begin{array}{l}(\beta) 150.5 \\
\left(\beta^{\prime}\right) 154.2\end{array}$ & 86.8 & 99.4 & 79.2 & 61.4 & 77.1 \\
\hline$\beta-C R-1200$ & $\begin{array}{l}\text { ( } \beta) 149.9 \\
\left(\beta^{\prime}\right) 153.7\end{array}$ & 88.5 & 99.2 & 79.1 & 62.8 & 75.6 \\
\hline$\beta-C R-1600$ & $\begin{array}{l}(\beta) 148.5 \\
\left(\beta^{\prime}\right) 153.0\end{array}$ & 85.8 & 99.2 & 78.2 & 64.2 & 70.9 \\
\hline
\end{tabular}

$\boldsymbol{T}_{\boldsymbol{m} \boldsymbol{p}}$ - peak temperature of melting of $\alpha$-modification, where $\beta$ and $\beta$ ' are the temperatures of the multiplied melting peaks 


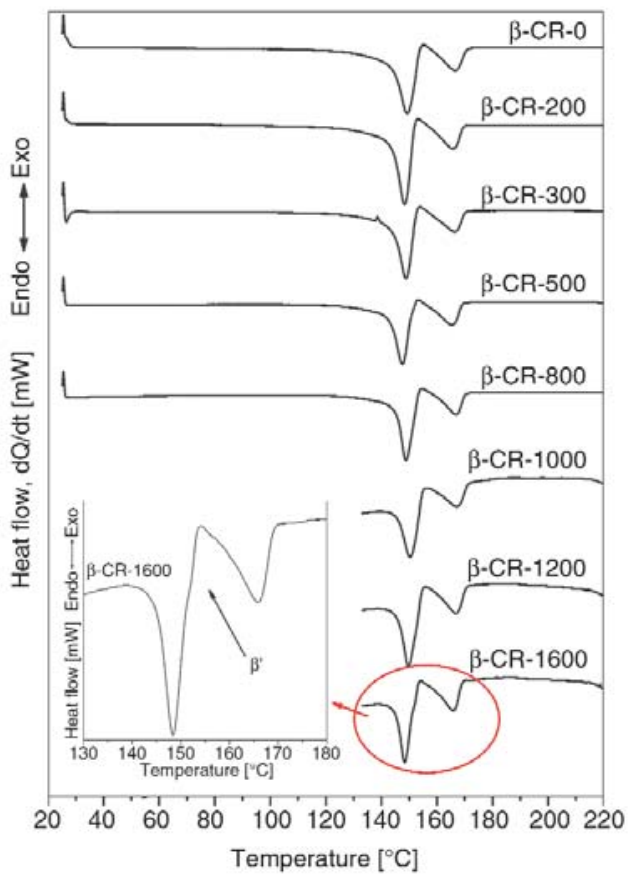

Figure 14. Melting curves of $\beta$-nucleated CR samples crystallized at cooling rate of $10^{\circ} \mathrm{C} / \mathrm{min}$ $\left(T_{R}=25^{\circ} \mathrm{C}\right)$

non-recooled melting curves recorded during heating from $100^{\circ} \mathrm{C}$ (Table 4).

\section{Conclusions}

The objective of this work was to investigate the effect of molecular mass on the crystallization tendency of the polymorphic modifications of iPP in wide range. The results prove that iPP crystallizes essentially in $\alpha$-form and the $\beta$-modification can be prepared by application of a highly active and selective $\beta$-nucleating agent in wide molecular mass range studied. The effect of molecular mass was studied on peroxide-degraded samples and a commercial iPP product with low molecular mass. Our results revealed that the decrease of molecular mass leads to increased structural instability of both $\alpha$ - and $\beta$-modification, which is manifested in decreasing of the melting temperature and in the enhanced inclination to the recrystallization during heating. The structural instability can be explained by the incorporation of the chain ends into the crystal lattices. The shorter the chains are the larger is the density of the incorporated chain ends and consequently the structural instability. The perfection process of unstable crystalline structure leads to pronounced $\alpha \alpha^{\prime}$ - and $\beta \beta^{\prime}$-peak duplication. In contrary to literature sources, which have reported that $\gamma$-modification forms in degraded samples and in low molecular mass iPP grades [18], $\gamma$-iPP could not detected in the samples studied. The recently used catalysts systems seem to provide highly stereoregular structure, which is not liable to crystallize in $\gamma$-form.

\section{References}

[1] Slichter W. P., Mandell E. R.: Spherulitic crystallization in polypropylene. Journal of Applied Physics, 30, 1479-1484 (1959). DOI: $10.1063 / 1.1734985$

[2] Lotz B., Wittmann J. J., Lovinger A. J.: Structure and morphology of poly(propylenes): A molecular analysis. Polymer, 37, 4979-4992 (1996). DOI: 10.1016/0032-3861(96)00370-9

[3] Varga J.: Crystallization, melting and supermolecular structure of isotactic polypropylene. in 'Polypropylene: Structure, blends and composites' (ed.: KargerKocsis J.) Chapmann and Hall, London, Vol 1, 56115 (1995).

[4] Varga J.: $\beta$-modification of isotactic polypropylene: Preparation, structure, processing, properties, and application. Journal of Macromolecular Science Part B: Physics, 41, 1121-1171 (2002).

DOI: $10.1081 / \mathrm{MB}-120013089$

[5] Menyhárd A., Varga J., Molnár G.: Comparison of different $\beta$-nucleators for isotactic polypropylene, characterisation by DSC and temperature-modulated DSC (TMDSC) measurements. Journal of Thermal Analysis and Calorimetry, 83, 625-630 (2006). DOI: $\underline{10.1007 / \mathrm{s} 10973-005-7498-6}$

[6] Varga J., Menyhárd A.: Effect of solubility and nucleating duality of $N, N^{\prime}$-dicyclohexyl-2,6-naphthalenedicarboxamide on the supermolecular structure of isotactic polypropylene. Macromolecules, 40, 24222431 (2007).

DOI: $\underline{10.1021 / \mathrm{ma} 062815 \mathrm{j}}$

[7] Leugering H. J.: Einfluss der Kristallstuktur und Überstuktur auf einige Eigeschaften von Polypropylen. Die Makromolekulare Chemie, 109, 204-216 (1967). DOI: 10.1002/macp.1967.021090118

[8] Shi G-Y., Zhang X-D., Qiu Z-X.: Crystallization kinetics of $\beta$-phase poly(propylene). Makromolekulare Chemie-Macromolecular Chemistry and Physics, 193, 583-591 (1992). DOI: $10.1002 / \mathrm{macp} .1992 .021930303$

[9] Ikeda N., Kobayashi T., Killough L.: Novel $\beta$-nucleator for polypropylene. in 'Polypropylene '96. World Congress', Zürich, Switzerland, 1-10 (1996).

[10] Xiao W. C., Wu P. Y., Feng J. C., Yao R. Y.: Influence of a novel $\beta$-nucleating agent on the structure, morphology, and nonisothermal crystallization behavior of isotactic polypropylene. Journal of Applied Polymer Science, 111, 1076-1085 (2009). DOI: 10.1002/app.29139 
[11] Varga J., Mudra I., Ehrenstein G. W.: Highly active thermally stable $\beta$-nucleating agents for isotactic polypropylene. Journal of Applied Polymer Science, 74, 2357-2368 (1999).

DOI: $\underline{10.1002 /(S I C I) 1097-4628(19991205) 74: 10<}$ 2357::AID-APP3>3.0.CO;2-2

[12] Zhang Z., Wang C., Yang Z., Chen C., Mai K.: Crystallization behavior and melting characteristics of $\mathrm{PP}$ nucleated by a novel supported $\beta$-nucleating agent. Polymer, 49, 5137-5145 (2008).

DOI: $10.1016 /$ j.polymer.2008.09.009

[13] Zhang Z., Tao Y., Yang Z., Mai K.: Preparation and characteristics of nano- $\mathrm{CaCO}_{3}$ supported $\beta$-nucleating agent of polypropylene. European Polymer Journal, 44, 1955-1961 (2008).

DOI: $10.1016 /$ j.eurpolymj.2008.04.022

[14] Varga J., Ehrenstein G. W., Schlarb A. K.: Vibration welding of alpha and $\beta$ isotactic polypropylenes: Mechanical properties and structure. Express Polymer Letters, 2, 148-156 (2008).

DOI: $10.3144 /$ expresspolymlett.2008.20

[15] Grein C., Gahleitner M.: On the influence of nucleation on the toughness of iPP/EPR blends with different rubber molecular architectures. Express Polymer Letters, 2, 392-397 (2008). DOI: $\underline{10.3144 / \text { expresspolymlett.2008.47 }}$

[16] Addink Miss E. J., Beintema J.: Polymorphism of crystalline polypropylene. Polymer, 2, 185-193 (1961). DOI: 10.1016/0032-3861(61)90021-0

[17] Phillips P. J., Mezghani K.: Polypropylene, isotactic (polymorphism). in 'The polymeric materials encyclopedy' (ed.: Salamon J. C.) CRC Press, Boca Raton, Vol 9, 6637-6649 (1996).

[18] Morrow D. R., Newman B. A.: Crystallization of lowmolecular-weight polypropylene fractions. Journal of Applied Physics, 39, 4944-4950 (1968). DOI: $10.1063 / 1.1655891$

[19] Wang S-W., Yang W., Xu Y-J., Xie B-H., Yang M-B., Peng X-F.: Crystalline morphology of $\beta$-nucleated controlled-rheology polypropylene. Polymer Testing, 27, 638-644 (2008).

DOI: $10.1016 /$ j.polymertesting.2008.04.004

[20] Chvatalova L., Navratilova J., Cermak R., Raab M., Obadal M.: Joint effects of molecular structure and processing history on specific nucleation of isotactic polypropylene. Macromolecules, 42, 7413-7417 (2009).

\section{DOI: $10.1021 / \mathrm{ma} 9005878$}

[21] Výchopnová J., Cermák R., Obadal M., Verney V., Commereuc S.: Effect of $\beta$-nucleation on crystallization of photodegraded polypropylene. Journal of Thermal Analysis and Calorimetry, 95, 215-220 (2009). DOI: $10.1007 / \mathrm{s} 10973-008-8892-7$
[22] Campbell R. A., Phillips P. J., Lin J. S.: The gamma phase of high-molecular-weight polypropylene: 1 . Morphological aspects. Polymer, 34, 4809-4816 (1993).

DOI: 10.1016/0032-3861(93)90002-R

[23] Brückner S., Meille S. V., Petraccone V., Pirozzi B.: Polymorphism in isotactic polypropylene. Progress in Polymer Science, 16, 361-404 (1991). DOI: 10.1016/0079-6700(91)90023-E

[24] Krache R., Benavente R., López-Majada J. M., Pereña J. M., Cerrada M. L., Pérez E.: Competition between $\alpha, \beta$, and $\gamma$ polymorphs in $\beta$-nucleated metallocenic isotactic polypropylene. Macromolecules, 40, 68716878 (2007).

DOI: $\underline{10.1021 / \mathrm{ma} 0710636}$

[25] Juhász P., Belina K.: Crystallization and morphology of propylene/pentene random copolymers. Journal of Reinforced Plastics and Composites, 20, 2-11 (2001). DOI: 10.1106/A7N4-7YFW-YG88-NDP8

[26] Juhász P., Varga J., Belina K., Belina G.: Efficiency of $\beta$-nucleating agents in propylene/alpha-olefin copolymers. Journal of Macromolecular Science Part B: Physics, 41, 1173-1189 (2002).

DOI: $\underline{10.1081 / \mathrm{MB}-120013090}$

[27] Sheng B-R., Li B., Xie B-H., Yang W., Feng J-M., Yang M-B.: Influences of molecular weight and crystalline structure on fracture behavior of controlledrheology-polypropylene prepared by reactive extrusion. Polymer Degradation and Stability, 93, 225-232 (2008).

DOI: 10.1016/j.polymdegradstab.2007.09.011

[28] Azizi H., Ghasemi I., Karrabi Q.: Controlled-peroxide degradation of polypropylene: Rheological properties and prediction of MWD from rheological data. Polymer Testing, 27, 548-554 (2008).

DOI: $10.1016 /$ j.polymertesting.2008.02.004

[29] Turner J. A., Aizlewood J. M., Beckett D. R.: Crystalline forms of isotactic polypropylene. Macromolecular Chemistry, 75, 134-158 (1964).

DOI: $10.1002 / \mathrm{macp} .1964 .020750113$

[30] Varga J.: Melting memory effect of the $\beta$-modification of polypropylene. Journal of Thermal Analysis, 31, 165-172 (1986).

[31] Varga J., Ehrenstein G. W.: High-temperature hedritic crystallization of the $\beta$-modification of isotactic polypropylene. Colloid and Polymer Science, 275, 511-519 (1997). DOI: $\underline{10.1007 / \mathrm{s} 003960050113}$

[32] Varga J., Karger-Kocsis J.: Rules of supermolecular structure formation in sheared isotactic polypropylene melts. Journal of Polymer Science Part B: Polymer Physics, 34, 657-670 (1996). DOI: $10.1002 /($ SICI) 1099-0488(199603)34:4<657:: AID-POLB6>3.0.CO;2-N 